советского строя только по названию, но не по своей сути. Нэп являлся кратким периодом возрождения кооперативной работы на транспорте, но не стал для нее золотым веком. Основанное на прикреплении к снабжающей организации членство, централизованное распределение фондов и жесткий партийно-государственный контроль лишали кооперативы статуса самодеятельных организаций. Казенщина вытесняла самодеятельность, предприимчивость и инициативу. Существовали и объективные сложности развития эффективной торговли в широко раскинувшейся сети торговых пунктов, часть из которых была неизбежно убыточной. К концу периода ТПО превратились в сеть закрытых распределителей, обслуживавших рабочих централизованно распределяемыми товарами по заборным карточкам. Это предопределило организационное поглощение кооперативных структур, что и произошло в 1933 г. с образованием в системе транспортной кооперации УРСов и передачей им кооперативной собственности. Кризисные явления в кооперации в конце 1920-х гг. были восприняты руководством как недееспособность и неприспособленность кооперативных форм для решения глобальных задач модернизации экономики. При этом выражение «кооперативные методы работы» в партийном языке превратилось в ярлык для работающих неповоротливо и нерадиво.

\section{СПИСОК ЛИТЕРАТУРЫ}

1. Николаев A.A. Основные виды кооперации в России: историко-теоретический очерк. Новосибирск, 2007. 280 с.
2. Люри Н. Общество потребителей служащих Забайкальской железной дороги: обзор деятельности за период 1899-1916 годов. Иркутск, 1917. $96 \mathrm{c.}$

3. Запорожченко Г.М. Транспортная кооперация Сибири в первой трети XX века. Новосибирск, 2007. 232 с.

4. Краткий отчет правления Омского ТПО о работе в $1926-$ 27 г. Омск, 1928.

5. Отчет о деятельности правления Красноярского районного ТПО за 1927-28 операционный год. Красноярск, 1929.

6. Отчет о работе Забайкальского ТПО за 1927-1928 отчетный год, 29-ый год существования. Чита, 1929.

7. Потребкооперация Сибири в 1927-1928 и 1928-1929 гг. Отчет IV Собранию уполномоченных Сибкрайсоюза. Новосибирск, 1930.

\section{REFERENCES}

1. Nikolaev A.A. The main types of cooperatives in Russia: historical and theoretical essays. Novosibirsk, 2007. 280 p. (In Russ.)

2. Lury $N$. The consumer society of Transbaikalian railway servants: review of activities for the period 1899-1916. Irkutsk, 1917. 96 p. (In Russ.)

3. Zaporozhchenko G.M. Transport cooperation in Siberia in the first third of the twentieth century. Novosibirsk, 2007. 232 p. (In Russ.)

4. A brief report of the Omsk Transport consumer society on the work in 1926-27. Omsk, 1928. (In Russ.)

5. The activity report of the Board of the Krasnoyarsk regional Transport consumer society for the fiscal year 1927-28. Krasnoyarsk, 1929. (In Russ.)

6. Report on the work of Transbaikalian Transport consumer society for 1927-1928 year, the 29th year of existence. Chita, 1929. (In Russ.)

7. The district of Siberia in 1927-1928 and 1928-1929. Report for IV Meeting of commissioners of Siberian regional consumer Union. Novosibirsk, 1930. (In Russ.)

\title{
Н.С. КОРОБЕЙНИКОВА
}

\section{ДЕТСКАЯ СМЕРТНОСТЬ В ГОРОДАХ ЗАПАДНОЙ СИБИРИ В ГОДЫ ВЕЛИКОЙ ОТЕЧЕСТВЕННОЙ ВОЙНЫ (1941-1945 ГГ.)*}

\author{
Надежда Сергеевна Коробейникова, \\ канд. ист. наук, младший научный сотрудник, \\ Институт истории СО РАН, \\ РФ, 630090, г. Новосибирск, ул. Николаева, 8 \\ e-mail: ellpise@gmail.com
}

\begin{abstract}
В статье изучается тренд детской смертности в годы Великой Отечественной войны как важнейший показатель воспроизводства населения. Выявлены структурные трансформации детской смертности в городах Западной Сибири в 1941-1945 гг. Прослежена динамика региональных показателей детской смертности на разных этапах военного времени. Выделены данные младенческой смертности, определена ее специфика и причины в годы войны. Кроме того, рассмотрены изменения уровня детской смертности по месяцам. Большое внимание уделено главным факторам, которые определяли динамику показателей детской смертности в условиях военного времени. Высказано предположение, что начавшееся сокращение общего показателя детской смертности оказало своеобразное влияние на уровень рождаемости
\end{abstract}

*Статья подготовлена при финансовой поддержке РГНФ, проект № 14-01-00109. 
в регионе. Тем не менее автор рассматривает альтернативное мнение Н.А. Семашко, который ставил под сомнение успехи советской медицины и определял основным фактором снижения показателей детской смертности интенсивные миграции военного времени.

Ключевые слова: детская смертность, детность, Великая Отечественная война, Западная Сибирь.

\title{
N.S. KOROBEYNIKOVA
}

\section{INFANT MORTALITY IN URBAN AREAS OF WEST SIBERIA DURING THE GREAT PATRIOTIC WAR (1941-1945)}

\author{
Nadezhda S. Korobeynikova, \\ Junior Researcher, \\ Institute of History SB RAS, \\ 8 Nikolaeva Str., Novosibirsk, 630090, Russia \\ e-mail: ellpise@gmail.com
}

A problem of changing quantitative indices of infant mortality aroused interest among the officials of the People's Commissariat of Health righ after World War II. Several reports were devoted to this issue at the medical-sanitary conference in 1946. Its participants represented not only the central health-care agencies but also the regional bodies. In the course of the discussions they noted the effectiveness of health measures undertaken during the war. In response to such optimistic reports of his colleagues N. A. Semashko urged to pay attention to active migrations that took place within the region during the war. Modern views on this issue remain heterogeneous, there does not exist any one single concept. The author studies various approaches to interpreting changes of quantitative indices of infant mortality in wartime and reveals dominant viewpoints in research literature at different stages of formation of demographical knowledge about the Great Patriotic War.

The paper shows factors that influenced decrease in infant mortality during the war based on a complex of statistical and narrative sources. The author studied indicators of monthly dynamics of postnatal mortality in 1941-19454; investigated causations of infant mortality for males and females in the age groups 0-4, 5-9, and 10-14 years; investigated specifics of interaction between the local health authorities and regional statistical agency concerning the problem of infant mortality and children's health protection. The article reflects a peculiar attitude of the People's Commissariat of Health towards a problem of rapid increase in infant mortality. The author substantiates an assumption that the reduction of infant mortality influenced the birth rate in the region.

Key words: infant mortality, number of children, Great Patriotic War, West Siberia.

Вплоть до зимы 1942/43 г. в городах Западной Сибири сохранялся высокий уровень детской смертности. Это не могло не беспокоить чиновников, ответственных за вопросы охраны материнства и детства. Еще в 1941 г. в «Сборник важнейших официальных и справочных материалов по санитарным и противоэпидемическим вопросам...», который был опубликован в 1941 г. под редакцией Наркома здравоохранения СССР Г.А. Митерева, была включена глава «Борьба с детскими инфекциями», где также было отмечено, что «организация и проведение борьбы с детскими инфекционными заболеваниями являются одной из важнейших задач советского здравоохранения». Основная ответственность за эту борьбу возлагалась на различные государственные органы, которые должны были координировать работу по здравоохранению [1, с. 483]. Н.В. Мананникова, которая контролировала проблемы охраны здоровья матери и ребенка, в годы войны опубликовала ряд печатных работ, в которых обрисовывала проблемный круг защиты материнства и детства. В конце 1940 г. она писала о том, что уровень детской заболеваемости по-прежнему остается высоким, а также рассуждала о путях его снижения [2, с. 1-4]. Решение проблемы высокого уровня детской заболеваемости в военное время она видела в количественном и качественном развитии детских дошкольных учреждений [3, 16-19]. Во всех этих работах проблема детской смертности обретала не только медицинский, но и социальный смысл.

В послевоенное время чиновники Наркомздрава пытались найти объяснение произошедшему на границе 1942 и 1943 гг. внезапному сокращению показателя как младенческой, так и детской смертности. Тот факт, что они не имели однозначного ответа на данный вопрос, свидетельствует о том, что для них это снижение также оказалось внезапным. На второй конференции, посвященной ликвидации медико-санитарных последствий войны в конце 1946 г., Г.Ф. Ершов, оценивая демографические результаты войны на материалах Молотовской области, пришел к выводу о том, что сокращение детской смертности в 1943-1945 гг. было результатом эффективной работы медицинских служб [4, с. 12-16]. Тем не менее у Н.А. Семашко имелось иное объяснение стремительного снижения показателя на завершающем этапе войны: «К сожалению, мы до сих пор не имеем статистических работ, в которых вопрос о детской смертности был бы изучен дифференцированно в отношении местных и прибывших детей... У меня большое опасение, что мы столь же необоснованно пугали высокими цифрами детской смертности, как и радовались резким снижением ее» [4, с. 27].

Несмотря на сомнения одного из основателей системы советского здравоохранения, специалисты по социальной гигиене сошлись во мнении, что со- 
кращение детской смертности в военное время было заслугой советской медицинской науки. Долгие годы эта точка зрения оставалась незыблемой. Так, Н.В. Мананникова в своих мемуарах связывала снижение уровня детской смертности с деятельностью яслей [5, с. 71]. С ней был согласен в своих мемуарах и Г.А. Митерев, который также был уверен в эффективности медицины [6, с. 185]. Этот подход оставался основным объяснением произошедших изменений вплоть до 2000-х гг.

В.А. Исупов в 2000 г. исследовал количественные трансформации детской смертности в военные годы. Ученый пришел к выводу о том, что, если в довоенный период на данный показатель влияли факторы биологического характера, в частности сезонный рост числа желудочно-кишечных заболеваний, то в 1942 1944 гг. усилилось значение социальных условий, таких как эвакуация, что выразилось в одинаковых темпах роста смертности мальчиков и девочек [7, с. 145]. В работе «Главный ресурс Победы» он исследует эту проблему применительно к западносибирскому региону более детально. Прослеживая зависимость между детской и младенческой смертностью и реалиями войны в отдельных областях, он пришел к выводу, что в 1941 и 1942 гг. экстремальные военные условия накладывались на сезонные колебания смертности, что обусловило высокий показатель числа смертей детей [8, с. 115-117]. По мнению ученого, сокращение уровня детской смертности, которое произошло в 1943 г,, объясняется действием таких факторов, как повышение внимания руководства страны к социальным проблемам тыла, не случайно снижение детской смертности происходило на фоне общего снижения смертности [8, с. 143]. Снижению этого показателя способствовало также сокращение рождаемости [8, с. 159]. Кроме того, В.А. Исупов в качестве отдельного вопроса изучил условия содержания детей в детских домах и сделал вывод о том, что в структуре причин смертности большое влияние оказывали условия содержания детей $[8$, с. 119-120].

Целью данной статьи является рассмотрение факторов, способствовавших сокращению детской смертности в годы войны, а также изучение социального значения изменений показателя. Территориальные рамки исследования - города Западной Сибири. Хронологически статья охватывает период с 1941 по 1945 г. Объектом исследования в настоящей статье выступает детская смертность в городах Западной Сибири в 1941-1945 гг., предметом - ее трансформации, их факторы и последствия. В настоящей статье используются статистические материалы, которые хранятся в архивах ГАРФ (ф. А-374, оп. 11) и ГАНО (ф. 11, оп. 2).

Высокий уровень младенческой смертности не был для Западной Сибири необычным явлением. Детская и младенческая смертность в годы войны была не просто биологическим показателем. Во многом она еще определялась существовавшими в обществе стереотипами. В работе «Демографическая модернизация
России» авторы обращают внимание на такую особенность существовавшего в обществе в начале XX в. отношения к смерти ребенка, как некоторое социальное равнодушие [9, с. 76]. Еще в 1940 г. беспокойство инспектора по поводу высокого уровня смертности младенцев в одной из больниц провинциального рабочего поселка Новосибирской области вызвало лишь недоумение у руководства:

24 августа 1940 г.

Отчет за июль месяц показывает уровень смертности детей до 1 года, составляющий 45\%. Причина смертности токсичная диспенсия. Такая смертность явилась следствием крайне неудовлетворительного медицинского обслуживания. Райздрав в июне, июле месяце отпустил в отпуск почти всех медицинских работников.

Инспектор Нархохучета Золотарев.

Руководство Нархозучета предприняло попытку разобраться в высокой смертности. Заведующей облздравом тов. Астафьевой был направлен запрос:

Из полученной информационной записки инспектора Нархозучета т. Золотарева отмечается увеличение детской смертности в возрасте до 1 года..., особенно по причине «токсическая диспенсия... Причиной этому является - неудовлетворительное медицинское обслуживание населения, к тому же с ведома и, вероятно, с согласия зав. Райздрава, медицинским работникам в июне и июле был предоставлен очередной отпуск. Таким образом, медицинская сеть в указанные месяцы осталась без медработников. В частности, в рабочем поселке Тогур не осталось ни одного работника Сектор населения и здравоохранения считает ненормальным действия в вопросе дачи отпусков - просит вмешаться и принять меры к прекращению высокого процента смертности.

Начальник сектора Населения и Здравоохранения тов. Поминов.

В деле отсутствует ответ тов. Астафьевой. Однако в ответе инспектору тов. Золотореву тов. Поминов ссылается на форму медицинского учета 97, данные которой, по-видимому, и стали ответом заведующей Облздравом.

\section{тов. Золотареву}

На Ваше от 20/VIII № 11120-8

По вопросу детской смертности в возрасте до 1 года за июль месяц сего года... Ваш сигнал проверен и результат таковой

$$
\begin{array}{cccc}
\multicolumn{2}{c}{\text { Июнь }} & \multicolumn{2}{c}{\text { Июль }} \\
\text { Родились } & \text { Умерли } & \text { Родились } & \text { Умерли } \\
9 & 2 & 15 & 4
\end{array}
$$

Показатели приведены по форме № 97.

Из приведенных цифр такого положения, о котором сообщаете (100\%), не усматривается, приведенные показатели являются нетождественными с данными Вашего дневника.

Зав. сектора Населения Поминов.

Таким образом, чиновники на разных уровнях управления в различных ведомствах не могли прийти к универсальному решению по поводу итогового числа детских смертей и их доли от числа новорожденных. При этом проблема состояния медицинского обслуживания, которое инспектор определял в качестве основного фактора высокой младенческой смертности, быстро исчезла из бюрократического диалога. Одна- 
Помесячная динамика смертности детей в возрасте до 1 года в городах Западной Сибири в 1941-1945 гг.* (расчеты приведены на 1000 рождений, представлены в \%о)

\begin{tabular}{|c|c|c|c|c|c|}
\hline Месяц & 1941 г. & 1942 г. & 1943 г. & 1944 г. & 1945 г. \\
\hline Январь & 164,78 & 205,98 & 169,70 & 91,92 & 60,86 \\
\hline Февраль & 195,34 & 233,94 & 178,51 & 110,43 & 71,91 \\
\hline Март & 169,48 & 226,65 & 138,02 & 94,53 & 90,99 \\
\hline Апрель & 239,48 & 293,35 & 159,69 & 101,86 & 91,08 \\
\hline Май & 236,99 & 346,82 & 181,43 & 73,92 & 81,60 \\
\hline Июнь & 264,11 & 637,96 & 254,73 & 84,11 & 102,80 \\
\hline Июль & 436,22 & 641,95 & 200,63 & 113,32 & 130,15 \\
\hline Август & 335,32 & 474,36 & 156,80 & 94,84 & 81,86 \\
\hline Сентябрь & 213,31 & 313,00 & 125,00 & 78,64 & 84,86 \\
\hline Октябрь & 218,18 & 233,21 & 104,30 & 95,22 & 76,88 \\
\hline Ноябрь & 255,16 & 272,43 & 82,00 & 76,61 & 68,95 \\
\hline Декабрь & 211,59 & 222,32 & 93,30 & 74,18 & 90,47 \\
\hline Итог & 241,96 & 327,35 & 152,28 & 90,53 & 85,82 \\
\hline
\end{tabular}

* Составлено по: ГАРФ. Ф. А-374. Оп. 23. Д. 442. Л. 3. 112; Оп. 11. Д. 39. Л. 3; Д. 40. Л. 3; Д. 77. Л. 3, 82; Д. 176. Л. 2, 62; Д. 225. Л. 3, 36, 82; Д. 293. Л. 3, 81; Д. 294. Л. 11, 69, 75, 76; Д. 380. Л. 2, 75, 127, 178, 182; ГАНО. Ф. 11. Оп. 2. Д. 607. Л. 5; Д. 736. Л. 2, 21; Д. 871. Л. 26, 27; Д. 992. Л. 18, 19, 20.

ко вопрос об эффективности медицинского обслуживания в городских поселениях Новосибирской области вставал не первый раз. В г. Новосибирске в том же 1940 г. сектор здравоохранения Нархозучета писал Объяснительную записку о том, что смертность, которая местами «превысила рождаемость», была «вызвана заболеванием детей корью», «а мер борьбы со смертностью со стороны Райздрава ведется не достаточно». Кроме того, по мнению чиновника, «Райздрав, видимо, плохо или совсем не посещает мед. пункты, расположенные на периферии района». Данная записка была составлена уже другим инспектором - Губаревым ${ }^{1}$. Фактически детская смертность была стихийным явлением, и у Наркомздрава оказалось мало ресурсов, чтобы остановить его.

Но, как уже было сказано выше, на границе 1942 и 1943 гг. произошел спад младенческой и детской смертности. Он имел устойчивый характер и стремился к дальнейшему сокращению.

В (табл. 1) представлены данные по динамике смертности детей в возрасте до 1 года на 1000 рождений с 1941 по 1945 г. Согласно приведенным данным, самый высокий уровень смертности детей до 1 года пришелся на 1942 г. По итогам года он составил 327,35 \%о, при том что предыдущий, 1941 г., закончился 241,96\%о смертей, а следующий, 1943 г. - 152,28 \%о. Максимальный по уровню смертности период долгое время приходился на летние месяцы. Однако уже с 1943 г. разница между летним и весенним периодом становится меньше, при том что в предыдущие годы она доходила почти до 100 \% (1942 г.). В 1944 и 1945 гг. общий уровень младенческой смертности снижается,

${ }^{1}$ ГАНО. Ф. 11. Оп. 2. Д. 480. Л. 236. хотя сезонные колебания сохраняются, но перестают быть настолько ярко выраженными, как в предыдущие годы.

Таким образом, за годы войны младенческая смертность дважды переживает значительные изменения. Первый раз, в связи с началом Великой Отечественной войны, обычное для летнего периода увеличение детской смертности совпадает с общим ухудшением условий жизни, которое было характерно для военного периода. Второй трансформационный период приходится на 1943 г. и характеризуется снижением младенческой смертности. Для 1944 и 1945 гг. было характерно снижение контраста уровня детской смертности между апрелем, июлем и октябрем. Самый высокий уровень смертности пришелся на лето 1942 г., когда в городах и городских поселениях на первом году жизни умирало более 60 \% детей. Самый низкий уровень показателя приходился на зимние месяцы 1945 г. В январе умерло только 60,86 \%о детей. Для понимания причин внезапного снижения смертности необходимо рассмотреть структурные трансформации детской смертности.

Структура детской смертности претерпела существенные изменения. Так, в городах Новосибирской области в 1941-1943 гг. на первом месте по числу смертей детей в возрасте до 1 года находились заболевания из группы приобретенные (в их число входили: менингит, болезни нервной системы, все виды воспалений легких, в том числе крупозное, токсическая диспенсия, острый гастероколит). Причем смертность среди мальчиков была более интенсивной, чем смертность среди девочек. В тот же период на втором месте по числу причин смерти детей в возрасте до 4 лет были инфекционные заболевания (в их число входили: корь, 
Т а б л и ц а 2

Изменения детской и подростковой смертности в городских поселениях Новосибирской области в 1941-1944 гг., \%о (расчеты приведены на 1000 чел.)*

\begin{tabular}{|c|c|c|c|c|c|c|c|c|c|c|c|c|}
\hline \multirow[b]{2}{*}{ Показатель } & \multicolumn{3}{|c|}{1941 г. } & \multicolumn{3}{|c|}{1942 г. } & \multicolumn{3}{|c|}{1943 г. } & \multicolumn{3}{|c|}{1944 г. } \\
\hline & $\begin{array}{c}0-4 \\
\text { года }\end{array}$ & $\begin{array}{l}5-9 \\
\text { лет }\end{array}$ & $\begin{array}{c}10-14 \\
\text { лет }\end{array}$ & $\begin{array}{c}0-4 \\
\text { года }\end{array}$ & $\begin{array}{l}5-9 \\
\text { лет }\end{array}$ & $\begin{array}{c}10-14 \\
\text { лет }\end{array}$ & $\begin{array}{c}0-4 \\
\text { года }\end{array}$ & $\begin{array}{l}5-9 \\
\text { лет }\end{array}$ & $\begin{array}{c}10-14 \\
\text { лет }\end{array}$ & $\begin{array}{c}0-4 \\
\text { года }\end{array}$ & $\begin{array}{l}5-9 \\
\text { лет }\end{array}$ & $\begin{array}{c}10-14 \\
\text { лет }\end{array}$ \\
\hline \multicolumn{13}{|c|}{ Мальчики } \\
\hline $\begin{array}{c}\text { Инфекционные } \\
\text { заболевания }\end{array}$ & 1,72 & 0,09 & 0,02 & 1,62 & 0,11 & 0,04 & 1,05 & 0,14 & 0,07 & 0,21 & 0,06 & 0,03 \\
\hline $\begin{array}{l}\text { Хронические за- } \\
\text { болевания }\end{array}$ & 0,57 & 0,06 & 0,05 & 0,45 & 0,06 & 0,06 & 0,86 & 0,19 & 0,10 & 0,23 & 0,05 & 0,04 \\
\hline $\begin{array}{c}\text { Приобретенные } \\
\text { заболевания }\end{array}$ & 3,45 & 0,06 & 0,02 & 3,49 & 0,08 & 0,01 & 3,26 & 0,10 & 0,06 & 0,91 & 0,07 & 0,02 \\
\hline $\begin{array}{l}\text { Детские заболе- } \\
\text { вания }\end{array}$ & 0,31 & 0 & 0 & 0,22 & 0 & 0 & 0,23 & 0 & 0 & 0,07 & 0 & 0 \\
\hline $\begin{array}{l}\text { Насильственная } \\
\text { смерть }\end{array}$ & 0,08 & 0,03 & 0,01 & 0,07 & 0,05 & 0,05 & 0,11 & 0,16 & 0,09 & 0,02 & 0,03 & 0,00 \\
\hline \multicolumn{13}{|c|}{ Девочки } \\
\hline $\begin{array}{c}\text { Инфекционные } \\
\text { заболевания }\end{array}$ & 1,65 & 0,09 & 0,02 & 1,54 & 0,13 & 0,03 & 0,96 & 0,12 & 0,06 & 0,26 & 0,05 & 0,02 \\
\hline $\begin{array}{l}\text { Хронические за- } \\
\text { болевания }\end{array}$ & 0,51 & 0,06 & 0,08 & 0,44 & 0,05 & 0,06 & 0,79 & 0,16 & 0,04 & 0,22 & 0,07 & 0,03 \\
\hline $\begin{array}{c}\text { Приобретенные } \\
\text { заболевания }\end{array}$ & 3,03 & 0,05 & 0,03 & 3,19 & 0,07 & 0,03 & 2,70 & 0,09 & 0,04 & 0,59 & 0,05 & 0,01 \\
\hline $\begin{array}{l}\text { Детские заболе- } \\
\text { вания }\end{array}$ & 0,23 & 0 & 0 & 0,17 & 0 & 0 & 0,19 & 0 & 0 & 0,10 & 0 & 0 \\
\hline $\begin{array}{l}\text { Насильственная } \\
\text { смерть }\end{array}$ & 0,06 & 0,02 & 0,004 & 0,05 & 0,02 & 0,01 & 0,08 & 0,03 & 0,02 & 0,05 & 0,07 & 0,01 \\
\hline
\end{tabular}

* Составлено по: ГАНО. Ф. 11. Оп. 2. Д. 607. Л. 81. Д. 736. Л. 38. Д. 871. Л. 54. Д. 991. Л. 36.

скарлатина, коклюш, дифтерия, грипп, дизентерия, гемоколит, полиомиелит, рожа, ангина). Заболевания, которые в исследуемый период квалифицировались как хронические (различные формы туберкулеза, врожденный сифилис), стабильно находились на третьем месте в списке причин детской смертности. Показательно, что при этом соотношение в пользу насильственной смерти в годы войны (убийство, несчастные случаи) стабильно сокращалось. Однако по-прежнему в когорте 0-4 года оно сохранялось на самом высоком уровне, что подтверждает высказанный ранее тезис о маргинализации материнства, а также о том, что запрет абортов, помимо роста числа случаев подпольных операций, сопровождался увеличением числа детоубийств. Самая маленькая доля детских смертей приходилась на детские заболевания (к ним относились болезни новорожденных, врожденные пороки и преждевременные роды). Данная группа заболеваний становилась причиной смерти в самой младшей возрастной когорте. Причем большинство смертей выпадало на возраст до 1 года (табл. 2).

Детская смертность, начав сокращаться в 1943 г., сохранила данную тенденцию в 1944 г., что подтверждает тезис об общем снижении этого показателя. Структурные трансформации также находились в рамках общерегиональных изменений причин сверхсмертности: приобретенные и инфекционные заболевания постепенно снижали свое влияние. Перелом, наступивший в 1943 г., свидетельствует о том, что в городах Западной Сибири врачи смогли справиться с бушевавшими эпидемиями, ежегодно становившимися причинами смерти множества детей.

В 1942 г. произошло важное событие в медицинской науке. Исследовательская группа под руководством 3.В. Ермольевой выработала на базе открытого ранее в 1940 г. в Оксфорде пенициллина русский аналог данного препарата [10]. Это достижение в области советской медицины оказало, пусть и не сразу, влияние на снижение смертности от инфекционных и воспалительных заболеваний, в том числе младенческих и детских. Многие болезни, такие как пневмония и ангина, ранее считавшиеся смертельными, стали излечимыми. В 1944 г. был выработан стрептомицин, который применялся при лечении туберкулеза. Таким образом, в годы войны ученые постепенно брали под контроль одни из самых опасных болезней.

Тем не менее Н.А. Семашко в 1946 г. недоверчиво отнесся к оптимистичным докладам о достижениях советской медицины, обратив внимание на фактор миграций, который в годы войны имел большое значение. 
По его мнению, «эвакуации были значительно вреднее для детей, чем обычные пики заболеваемости» [1, c. 27]. Однако о том, что он недооценил медицинский фактор, косвенно свидетельствуют демографические трансформации, произошедшие в годы войны. Сокращение уровня рождаемости в военное время также позволяет говорить о том, что показатели детской смертности изменились.

Уровень детской смертности частично влиял и на детность, которая в экстремальных условиях неожиданно также оказалась одним из действующих факторов снижения рождаемости. Количество детей, которые оставались живыми, влияло на число рождений в семье. Уже в 1930-е гг. среднестатистическая российская родительская пара имела свои репродуктивные идеалы по поводу ожидаемого числа детей [11, c. 38]. Иными словами, ограничение рождаемости, которое получило широкое распространение в России, несмотря на все попытки правительства противодействовать этому, являлось следствием того, что люди имели собственные представления о желаемом числе детей в семье. Представления о детности играли ключевую роль в ограничении рождаемости со стороны женщин. Таким образом, когда семья достигала желаемого уровня детности, она чаще всего начинала принимать меры с целью предупредить рождение новых детей. Контроль над рождаемостью становился социальной нормой.

Поскольку данная практика к концу 1930-х гг. приобрела массовый характер, она оказывала влияние на общее число рождений в регионе. В.А. Исупов, проанализировав социальные показатели рождаемости в России в годы Второй мировой войны, приходит к выводу, что в послевоенный период «...рождаемость постепенно становилась все более контролируемой. Вопреки воле правительства, женщины, родив ребенка в молодом возрасте, в дальнейшем уклонялись от деторождения» [7, с. 228]. Таким образом, данная тенденция становилась все более устойчивой в течение всех лет войны. Еще в 1939-1940 гг. основное число рождений приходилось на женские когорты 20 24 года и 25-29 лет. К 1945 г. эта ситуация усугубляется. На завершающих этапах войны немного вырастает рождаемость в когорте 30-34 года - так называемые отложенные рождения (фактически к 1945 г. это были женщины, которые в 1940 г. находились в когорте $25-$ 29 лет). Переместившиеся в потенциально наиболее репродуктивную когорту женщины 1921-1925 годов рождения имели новые репродуктивные идеалы. Для них желаемое число детей стало значительно меньше, чем у их предшественниц. Таким образом, за годы войны детность все больше влияла на уровень рождаемости, вызывая сокращение последней.

Одним из определяющих уровень детности показателей было изменение младенческой и детской смертности: если семье удавалось сохранить жизнь ребенку, следующее рождение она планировала или по прошествии некоторого времени или же не плани- ровала вовсе. Бесконтрольная рождаемость в пределах физиологических возможностей матери к концу 1930-х гг. уже давно стала историей. Городская семья обзаводилась тем числом детей, которое теоретически могла прокормить и разместить на своей скромной жилплощади.

Таким образом, сокращение детской смертности в период войны происходило частично под влиянием медицинского фактора. Изобретение новых лекарств, повышенное внимание со стороны чиновников постепенно накапливало положительный эффект. Безусловно, определенную роль играли и статистические огрехи, которые возникали в связи с интенсивными миграциями в годы войны.

Однако снижение младенческой смертности, которое пришлось на 1943 г., совпадает со спадом рождаемости в том же году. Практически невозможно определить в количественных показателях, какое значение имел этот фактор. Однако несомненно, он играл свою роль в том, что рост рождаемости в последние два года войны имел показатели ниже, чем в 1941 и 1942 гг. В сочетании со все усиливающейся концентрацией рождаемости в молодых возрастных группах эта особенность динамики показателя играла все бо́льшую роль в снижении рождаемости. Родители, планируя рождение малого числа детей, что было характерно для городских жителей еще в непростые 1930-е гг. [12, с. 75-85], останавливались на желаемой детности семьи.

\section{СПИСОК ЛИТЕРАТУРЫ}

1. Митерев Г.А. Борьба с детскими инфекциями // Сборник важнейших официальных и справочных материалов по санитарным и противоэпидемическим вопросам в помощь госсанинспектору и эпидемиологу. М., 1941. С. 481-485.

2. Мананникова Н.В. Основные задачи в области охраны здоровья детей в 1941 г. // Вопросы материнства и младенчества. 1940 № 12. C. $1-4$.

3. Мананникова Н.В. Охрана здоровья матери и ребенка в СССР // Медицинская сестра. 1942. Вып. 1, № 11-12. С. 16-19.

4. Ершов Г.Ф. Демографические последствия войны в Молотовской области // Медико-санитарные последствия войны и мероприятия по их ликвидации: Труды Второй конф. (17-19 декабря 1946 г.). M., 1948. T. 2. C. 12-15.

5. Мананникова Н.В. Охрана здоровья детей в СССР. М., 1973. $302 \mathrm{c}$.

6. Митерев Г.А. В дни мира и войны. М., 1975. 255 с.

7. Исупов B.A. Демографические катастрофы и кризисы в первой половине ХХ века. Новосибирск, 2000. 244 с.

8. Исупов В.A. Главный ресурс Победы. Людской потенциал Западной Сибири в годы Второй мировой войны (1939-1945 гг.). Новосибирск, 2008. 378 с.

9. Демографическая модернизация России. 1900-2000. М., 2006. 608 c.

10. Миндич Д.А. По жизненным показаниям... // Энергия промышленного роста. Великая Победа: люди, опыт, техника. М., 2010. C. 21-27.

11. Bongaarts J., Sobotka T. A demographic explanation for the recent rise in European fertility // Population and development review, 2012, March, N 83-120. P. 38-52.

12. Араловеи Н.А. Городская семья в России, 1927-1959 гг. Тула, 2009. 304 с. 


\section{REFERENCES}

1. Miterev G.A. Infantile infections control. Sbornik vazhneyshih ofitsialnyih i spravochnyih materialov po sanitarnyim $i$ protivoepidemicheskim voprosam v pomosch gossaninspektoru $i$ epidemiologu. Moscow, 1941, pp. 481-485. (In Russ.)

2. Manannikova N.V. Main tasks of children health protection in 1941 Voprosyi materinstva i mladenchestva. 1940, N 12, pp. 1-4. (In Russ.)

3. Manannikova N.V. Mother and child health care in the USSR Meditsinskaya sestra. 1942, vol. 1, N 11-12, pp. 16-19. (In Russ.)

4. Ershov G.F. Demographical consequences of the War in Molotov region. Mediko-sanitarnyie posledstviya voynyi i meropriyatiya po ih likvidatsii. Trudyi Vtoroy konferentsii (17-19 dekabrya 1946 g.). Moscow. 1948, vol. 1, pp. 12-15. (In Russ.)

5. Manannikova N.V. Infant health care in the USSR. Moscow, 1973, 302 p. (In Russ.)

6. Miterev G.A. In time of peace and war. Moscow, 1975, $255 \mathrm{p}$ (In Russ.)
7. Isupov V.A. Demographical catastrophes and creeses in Russia in the first half of the XX century. Novosibirsk, 2000, 244 p. (In Russ.)

8. Isupov V.A. The Victory main resourse. A human potential of West Siberia during World War II (1939-1945). Novosibirsk, 2008 , 378 p. (In Russ.)

9. Demographic modernization in Russia, 1900-2000. Moscow, 2006. 608 p. (In Russ.)

10. Mindich D.A. On a vital prescription ... Energiya promyish lennogo rosta. Velikaya Pobeda: lyudi, opyit, tehnika. Moscow, 2010, pp. 21-27. (In Russ.)

11. Bongaarts $J$., Sobotka T. A demographic explanation for the recent rise in European fertility. Population and development review, 2012, March, N 83-120, pp. 38-52.

12. Aralovets N.A. An urban family in Russia, 1927-1959. Tula, 2009, 304 p. (In Russ.)

Статья принята редакиией 09.07.2015

DOI: $10.15372 / \mathrm{HSS} 20150318$

УДК 94(47)»1941/45»

\title{
М.В. ШИЛОВСКИЙ
}

\section{СОВЕТСКИЕ АСЫ В ВЕЛИКОЙ ОТЕЧЕСТВЕННОЙ ВОЙНЕ 1941-1945 ГГ.} Часть 2

\author{
Михаил Викторович Шиловский, \\ д-р ист. наук, заведующий сектором, \\ Институт истории СО РАН, \\ РФ, 630090, Новосибирск, ул. Николаева, 8 , \\ e-mail: kapital@history.nsc.ru
}

\begin{abstract}
Статья основана на сведениях, собранных и систематизированных М.Ю. Быковым в справочнике «Асы Великой Отечественной. Самые результативные летчики 1941-1945 гг.» 2007 г., о 1114 летчиках-истребителях советских ВВС, участвовавших в Великой Отечественной войне. Эта элитарная группа анализируется с позиция участия в боевых действиях и количества сбитых фашистских самолетов. Устанавливаются типы отечественных истребителей и полученных от союзников по ленд-лизу, анализируется количество сбитых фашистских самолетов. Все поименованные в источнике родились в первой четверти XX в. и находились во время войны в возрасте до 40 лет. Их вклад в завоевание господства в воздухе составил 23974 индивидуально и 3315 коллективно сбитых самолетов противника, всего 27289 боевых машин (24,5 на каждого), или 48 \% от общего количества уничтоженных на советско-германском фронте. Отечественное производство стало материальной основой завоевания советскими ВВС господства в воздухе; незначительную часть самолетов, на которых воевали советские асы (2 \%), составили истребители, полученные по ленд-лизу.
\end{abstract}

Ключевые слова: Великая Отечественная война 1941-1945 г2., летчик-истребитель, ас, господство в воздухе, государственные награды, воинские звания, ВВС РККА, истребительный авиаполк, самолеты противника.

\section{M.V. SHILOVSKY}

\section{SOVIET ACE PILOTS IN THE GREAT PATRIOTIC WAR OF 1941-1945.}

Part 2

Mikhail V. Shilovsky, Doctor of Historical Sciences, Head of Department, Institute of History SB RAS, 8 Nikolaev Str., Novosibirsk, 630090, Russia e-mail: kapital@history.nsc.ru 